\title{
INVESTIGATING THE EFFECT OF THE VARIOUS STIFFNESS COEFFICIENT ON THE CONTROLLED DAMPER MASS SPRING SYSTEM BASED
}

\section{ON THE ELECTROMECHANICAL SENSOR}

\author{
MUNAF FATHI BADR, ADIL ABED NAYEEIF \& WISAM ADIL MUSTAFA
}

Department Mechanical Engineering, College of Engineering, Mustansiriyah University, Baghdad, Iraq

\begin{abstract}
This work is concerned with investigation the effect of the stiffness coefficient for the spring elements in the mechatronics applied system consists of damper mass spring system linked to the electrical position sensor. The suggested approach contains experimental work as well as theoretical analysis to meet the demand of the proposed system. In the application of the system; the practical work requires to set up a test rig involves the apparatus as well as three models of spring which has been selected to achieve the desired performance. It has been treated as un-damped vibrations case to measure the tolerance in the displacement distance with respect to specified reference point due to apply various values of mechanical load. The electrical position sensor has been used to convert the obtained values of the displacement distance to corresponding value of electrical signal which has been sent to electrical control unit. Comparison between practical and theoretical results has been carried out to realize the best results of the employed system. The simulation process results with using Matlab software package showed that there is a much greater similarity between the obtained practical and theoretical results and the proposed model can be applied with high efficiency. The little bit difference between theoretical and practical results may be occurred due to the accuracy of the employed measurement devices.
\end{abstract}

KEYWORDS: Electromechanical System, Position Sensor \& Simulation Process

Received: Feb 28, 2019; Accepted: Mar 18, 2019; Published: Apr 16, 2019; Paper Id.: IJMPERDJUN201928

\section{INTRODUCTION}

Nowadays, damper mass spring system is widely applied in a variety of industrial engineering applications such as vehicle suspension system [1]. It is one of the most important component in vehicles which has been designed and arranged to provide several advantages such as providing smooth ride over rough ground, leading to improve the comfort quality of riding and gain more safety versus dynamical and impact forces [2]. In fact dampers mass spring system consists of passive and active element which can be added to a mechanical vibration system in order to achieve better performance [3]. Passive control element involves some form of structural category, its often including the use of springs and dampers while an active control element such as sensors, actuators and some form of electronic control system can be used to provide more reliability of the control system and that leads to make a reduction in the measurement of vibration level [4-8]. Over the last decade, it can be noted that the various configuration of damper mass spring systems has been arranged and developed to meet different design requirements of the engineering application system to maintain control action [8-10]. Lots of employed mechanical structure contain spring element in addition to shock absorber which can be considered as the most important elements in reduction the structural vibration [5-7]. The air springs type can be considered as the most common 
type that are used in suspensions system. Actually they have several advantages over metallic counterparts in improvement the behavior of vibration control system. They can be founded in most of the commercially available passenger cars which have been equipped with passive spring and damper suspension systems [1-3]. The purpose of this work is to design and implementation a controlled model of damper mass spring system which mainly consists of spring, dashpot and electromechanical position sensor. The position sensor is fed by electrical circuit that has been designed to detect the net displacement in the system according to set point that has been previously selected. The measurement process of the tolerance in the distance has been carried out with using three different types of spring stiffness coefficient and applying different values of mechanical loads. The practical results of the experimental work has been compared with theoretical results to testify the best response of the system. This paper has been organized as in the following; the construction of the employed damper mass spring systems are given in section 2. Section 3 describes the mathematical models while the experimental results and Matlab simulation process are presented in section 4, followed by conclusions in section 5 .

\section{CONSTRUCTION OF ELECTROMECHANICAL SYSTEM}

The construction of proposed electromechanical damper mass spring system can be subdivided into electrical and mechanical subsystem. The electromechanical system consists of series combination of damper and spring elements mounted in vertical direction and interfacing with electrical position sensor as shown in Figure 1.

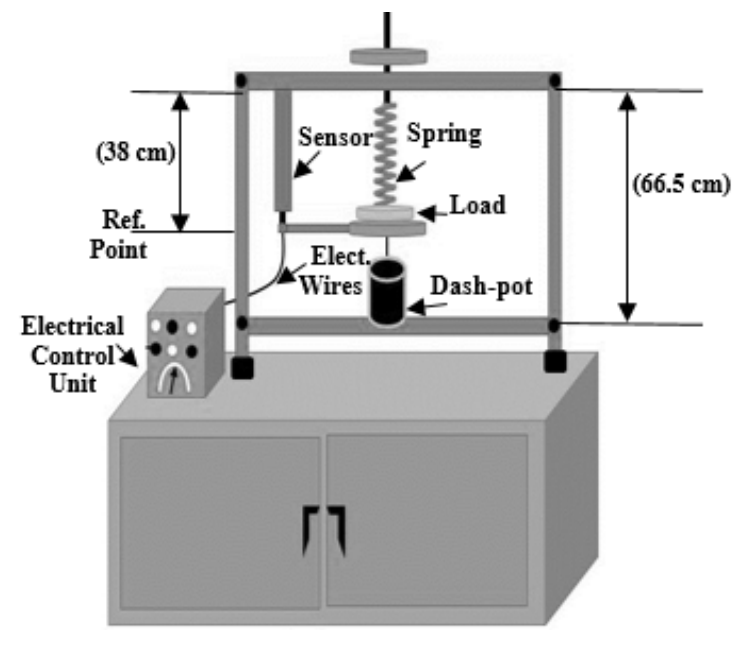

Figure 1: The Construction of Electromechanical Damper Mass Spring System

The electrical position sensor has been selected as a variable resistance element. It represents the basic element of the control unit of the suggested electromechanical system. It contains a movable iron core that provide a linear sliding contact with fixed resistance [11-12]. It has been fed with an appropriate level of electrical energy via electrical circuit that especially designed for converting the specified value of the tolerance in the linear motion to the corresponding electrical signal and sent it to the control unit as shown in Figure 2. 


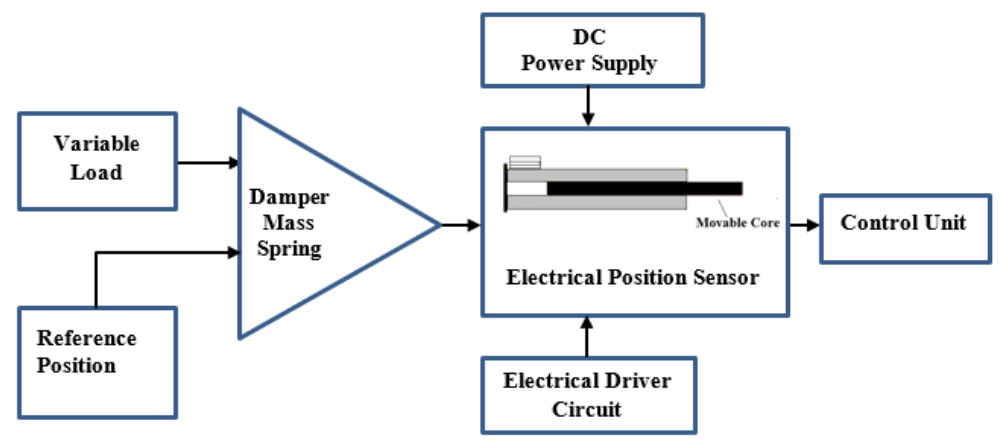

Figure 2: The Schematic Diagram of Electromechanical System

The movable core of the resistance was mechanically linked in parallel with damper mass spring system to ensure that it detect any difference in the position of the system may be appear due to apply variable values of mechanical load with respect to the specified reference point. The sensor was also equipped with mechanical stop to limit the minimum and maximum value of the electrical resistance. The process of measurement the tolerance in the distance of the damper mass spring system will be done according to use three models of spring as shown in Figure 3.
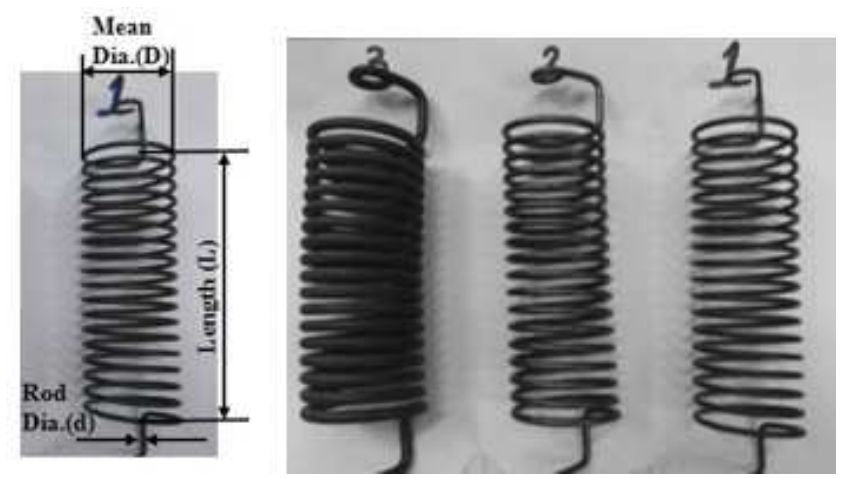

Figure 3: The Employed Different Types of Spring

Each selected spring will be inserted in the electromechanical system alone and separately to other springs to verify its effect on the response of the system. The characteristics of the employed springs can be summarized as shown in Table 1.

Table 1: The Characteristics of Employed Springs

\begin{tabular}{|l|c|c|c|}
\hline \multicolumn{1}{|c|}{ Item } & Spring1 & Spring2 & Spring3 \\
\hline No. of coils & 18 & 18 & 18 \\
\hline Mean diameter $(\mathrm{mm})$ & 43 & 44.5 & 48 \\
\hline Rod diameter $(\mathrm{mm})$ & 2.5 & 3 & 4.5 \\
\hline Length $(\mathrm{mm})$ & 135 & 128 & 124 \\
\hline
\end{tabular}

As well as the springs, the dashpot that used in the electromechanical system represents the type of the required damping forces subsystem. It has been filled with an appropriate fluid type inflammable hydraulic oil (talus 150) that has been carefully selected and implemented according to the characteristics of dash pot as shown in Table 2 . 
Table 2: The Characteristics of Dash-pot

\begin{tabular}{|l|c|}
\hline \multicolumn{1}{|c|}{ Item } & Properties \\
\hline Density of oil $\left(\mathrm{kg} / \mathrm{m}^{3}\right)$ & 882.7 at $150^{\circ} \mathrm{C}$ \\
\hline Viscosity of oil $(\mathrm{cst})$ & $135-165$ at $40^{\circ} \mathrm{C}$ \\
\hline Length of Cylinder, $\mathrm{Ld}(\mathrm{mm})$ & 120 \\
\hline Outer Diameter, Do $(\mathrm{mm})$ & 49.5 \\
\hline Inner Diameter, Di $(\mathrm{mm})$ & 44.5 \\
\hline Diameter of Piston, Dp(mm) & 41 \\
\hline Diameter of punch $(\mathrm{mm})$ & 6.5 \\
\hline
\end{tabular}

\section{THEORETICAL CALCULATIONS}

In this work, the theoretical calculation will be primarily depended on the fundamental electrical and mechanical laws. These laws will be applied on the suggested design of the electromechanical system which had been depicted as shown in Figure 4.

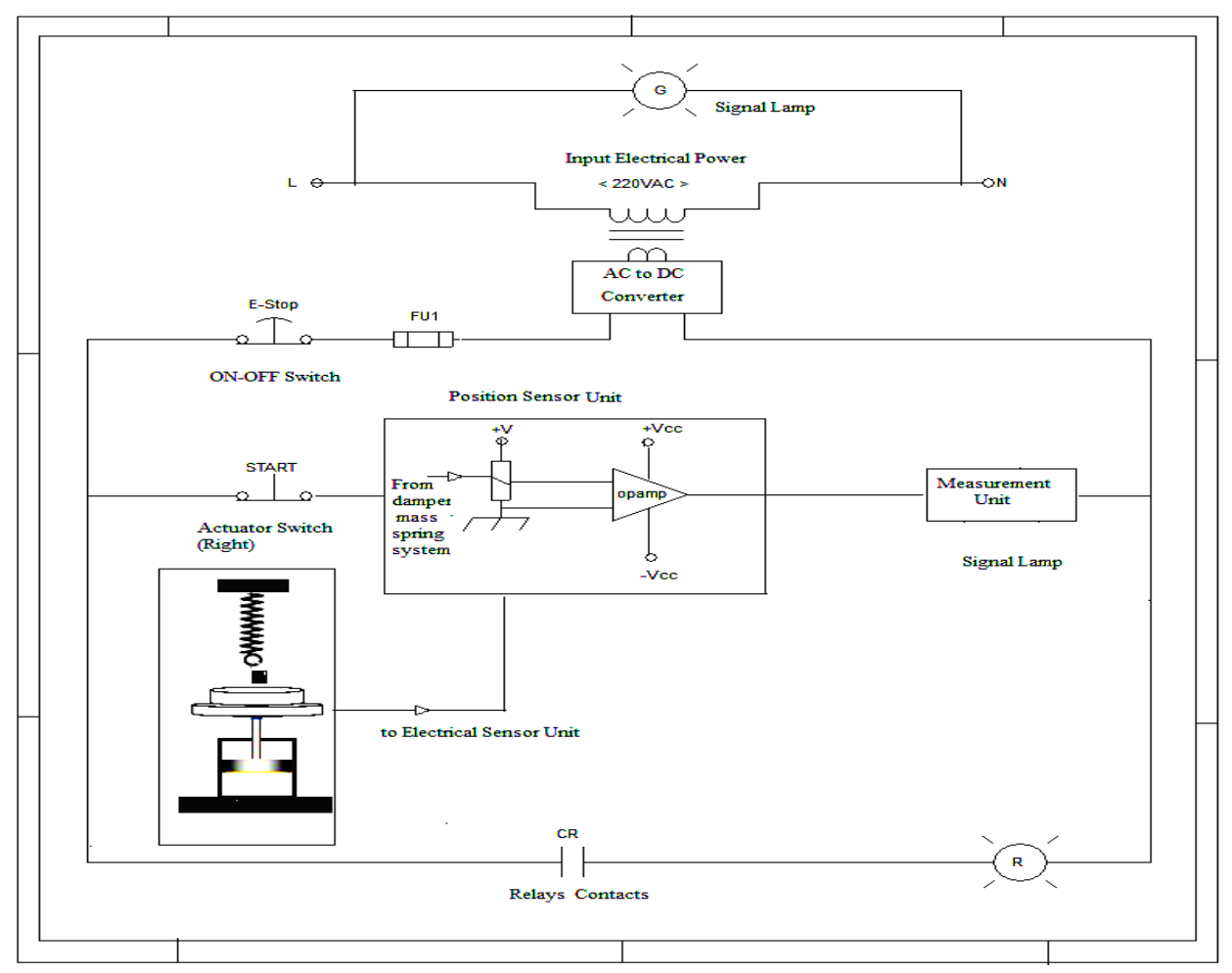

Figure 4: The Layout of the Controlled Electromechanical System

According to the characteristics of the employed position sensor; it can be noted from the practical test that the sensor behaves as variable resistance, then the output voltage signal from the sensor unit can be determined as in the following[13]:

$$
\begin{aligned}
& V_{\text {sensor }}=I_{\text {sensor }} \times R_{\text {sensor }} \\
& I_{\text {sensor }}=I_{\text {total }}=\frac{V_{\text {total }}}{R_{\text {total }}}
\end{aligned}
$$

Rearranging equation (2), then 


$$
V_{\text {sensor }}=V_{T} \times \frac{R_{\text {sensor }}}{R_{\text {total }}}
$$

Where

$V_{\text {sensor }}, V_{T}$ are the output voltage from the sensor and the total applied voltage $(\mathrm{V}) . R_{\text {sensor }}, R_{T}$ are the resistance of the sensor in which the voltage across it is required and the total resistance $(\Omega)$.

In the applied system, the output voltage signal from the sensor (Vsensor) is directly proportional to the variation of distance produced due to the effect of the force in the damper mass spring system. The change in position has been also depend on the various stiffness and damping coefficients of the spring and dash pot with different value of the mechanical load as shown in Figure 5.

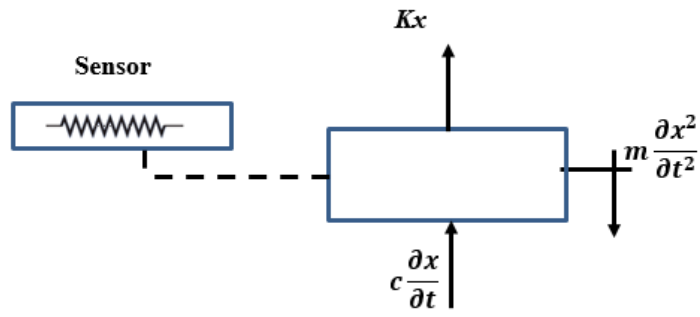

Figure 5: The Free Body Diagram of Electromechanical System

The employed mechanical system represents an oscillatory system which consists of three kinds of elements, the first item is a mass $(\mathrm{m})$ measured in $(\mathrm{kg})$, the second one is a damped coefficient (c) measured in (Ns/m) and finally the spring constant $(\mathrm{k})$ measured in $(\mathrm{N} / \mathrm{m})$. It can be mathematically determined the change of the movement $\mathrm{x}(\mathrm{t})$ with respect to time of the movement $\mathrm{x}(\mathrm{t})$ according to the second order dynamical differential equation and obtained net the force as in the following [14-17]:

$$
F=m \frac{\partial^{2} x}{\partial t^{2}}+c \frac{\partial x}{\partial t}+k x
$$

According to the mathematical model in (4), the transfer function $\left(T_{1}\right)$ of mechanical control system can be obtained with taking the Laplace transformation as in the following [17-18]:

$$
T_{1}=\frac{X(s)}{F(s)}=\frac{1}{\left(m s^{2}+c s+k\right)}
$$

Since the employed type of sensor can be represented as variable resistance with linear translation, then the transfer function of the position sensor $\left(T_{2}\right)$ can be calculated as follows:-

$$
T_{2}=\frac{V}{x}
$$

Hence, the overall transfer function $\left(T_{\text {open }}\right)$ of the electromechanical controlled system in the case of open loop control model will be as in equation(7).

$$
T_{\text {open }}=\frac{V}{x\left(m s^{2}+c s+k\right)}
$$


While in the closed loop controlled model with unity feedback, the mathematical model $\left(T_{\text {closed }}\right)$ can be written as in the following:-

$$
T_{\text {Closed }}=\frac{\frac{V}{x}}{\left(m s^{2}+c s+k+\frac{V}{x}\right)}
$$

In order to calculate the damping factor of the overall system, it can be used the equation of motion for rigid rectangular beam under excitation motor with spring and dash-pot system. This mathematical equation will be applied with using the three models of the spring and it can be written as in follows [14-16].

$\ddot{\theta}+\alpha \dot{\theta}+\beta \theta=0$

Where

$\alpha=\frac{C L_{1}^{2}}{J}, \beta=\frac{K L_{3}^{2}}{J}$,

$K=$ spring coefficient $(\mathrm{N} / \mathrm{m})$

$C=$ Damping coefficient of dash-pot (N. sec/m)

$L_{l}=$ Lengths of dash $-\operatorname{pot}(\mathrm{m})$

$L_{3}=$ Length of spring $(\mathrm{m})$

$J=$ mass moment of inertia $\left(\mathrm{kg} \cdot \mathrm{m}^{2}\right)$

Hence, equation (9) can be written as in the following:

$\ddot{\theta}+2 \xi \omega_{n} \dot{\theta}+\omega_{n}^{2} \theta=0$

Where

$\zeta=$ damping factor

$w_{n}=$ Natural frequency $(\mathrm{rad} / \mathrm{s})$

Based on the logarithmic decrement ratio between any two successive amplitudes, then the $(\delta)$ can be written as:-

$$
\delta=\frac{2 \pi \xi}{\sqrt{1-\xi^{2}}}=\ln \frac{x_{1}}{x_{2}}
$$

\section{EXPERIMENTAL AND SIMULATION RESULTS}

The electromechanical system has been set up in the vibration laboratory of mechanical department in the college of engineering of Mustansiriyah University as shown in Figure 6. 


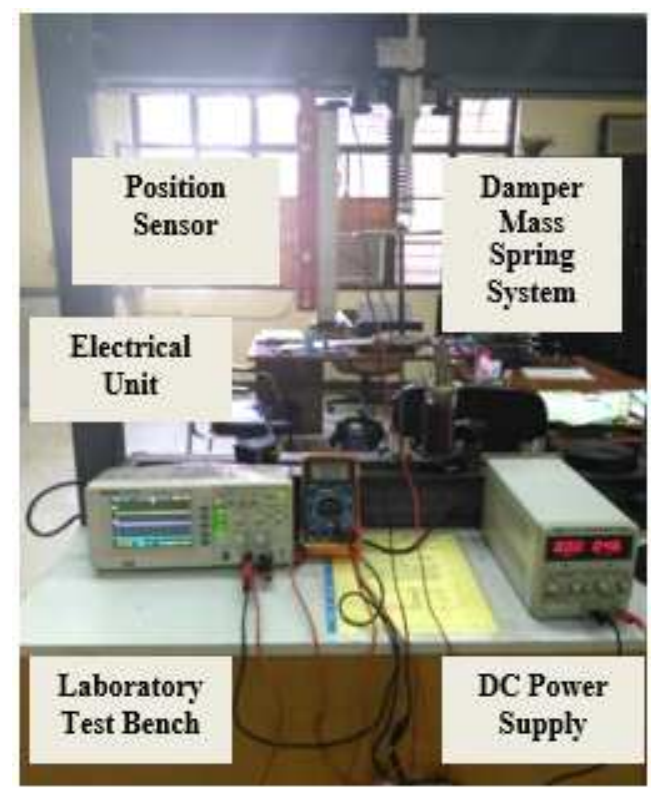

Figure 6: The Laboratory Electromechanical Test Bench

The test rig contains spring which represents as an elastic element, damper element, mass element and electrical control circuit with position sensor. The first step of the experimental work represents the implementation of practical tests for the available three models of springs in the laboratory to determine their stiffness value. To carry out this procedure, the calibration process of the equilibrium position has been taken as (xo = 56 mm) for spring (1) and $(128 \mathrm{~mm}),(33.5 \mathrm{~mm})$ for springs (2) and (3) respectively. The stiffness of the springs will be obtained practically under applied different values of mechanical load and measured the displacement distance that occurred in the position of the spring with respect to the equilibrium position point. The position sensor will be moved according to the variation of the stiffness coefficient of the spring and sent a corresponding electrical signals to electrical unit. The obtained results of the calibration process of the electromechanical system are listed as shown in Table 3.

Table 3: Calibration Test of Electromechanical System

\begin{tabular}{|c|c|c|}
\hline Spring Type & Equilibrium Position(cm) & Electrical Signal (V) \\
\hline 1 & 41 & 0.1 \\
\hline 2 & 41.2 & 0.147 \\
\hline 3 & 43.1 & 0.419 \\
\hline
\end{tabular}

After calibration process, the displacement that occur in the position of the system with respect to the equilibrium under applied different values of mechanical load can be measured as shown in Table 4.

Table 4: The Results of displacement for three types of springs

\begin{tabular}{|c|c|c|c|c|c|}
\hline \multicolumn{2}{|c|}{$\begin{array}{c}\text { Spring (1) } \\
\text { K1= 408.2 N/m }\end{array}$} & \multicolumn{2}{c|}{$\begin{array}{c}\text { Spring (2) } \\
\text { K2=922.9 N/m }\end{array}$} & \multicolumn{2}{c|}{ K3= 3557.5 N/m } \\
\hline Load (g) & Distance (mm) & Load (g) & Distance (mm) & Load (g) & Distance (mm) \\
\hline 400 & 66 & 400 & 133 & 1200 & 36.5 \\
\hline 800 & 75 & 800 & 137 & 2400 & 40 \\
\hline 1200 & 84 & 1200 & 141.5 & 3600 & 43 \\
\hline 1600 & 95 & 1600 & 145.5 & 4800 & 46 \\
\hline 2000 & 104 & 2000 & 150 & 6000 & 50 \\
\hline
\end{tabular}


The second step of the experimental work is to carry out the practical calculations of the damping coefficient (C)by using the vibration apparatus test bench in the laboratory as shown in Figure 7. According to the specified requirements and dimensions, the process of calculations the damping coefficient practically has been done with taking into account the mass of the motor $(\mathrm{M})$ with discs which is equal to $(4.102 \mathrm{~kg})$ and the mass of beam $(\mathrm{m}=2 \mathrm{~kg})$ in addition to the length of the beam $(\mathrm{L}=73 \mathrm{~cm})$.

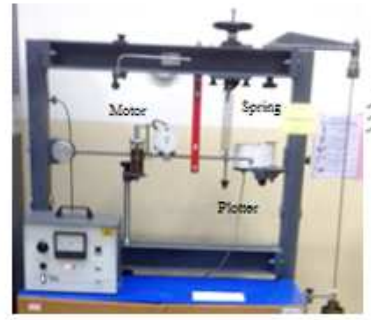

(a)

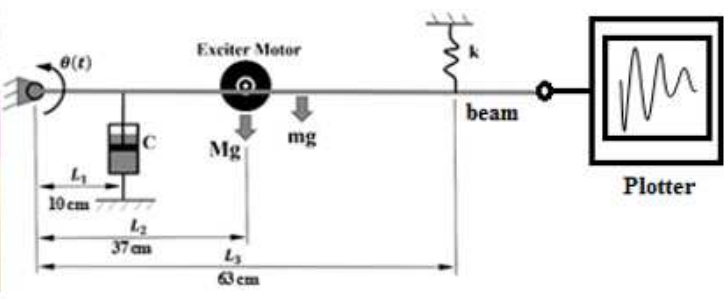

(b)

Figure 7: The Practical Calculation Process of Damping Coefficient (a) Vibration Test Bench (b) Schematic Diagram of Test Rig

The practical procedure of calculations the damping coefficient starts with movement the beam in the test bench in downward direction and vertical displacement equal to $(1.5 \mathrm{~cm})$ and then release it to isolate freely. The plotter device linked with the beam in the test bench will record the results of the response which has been occurred as shown in Figure 8 .

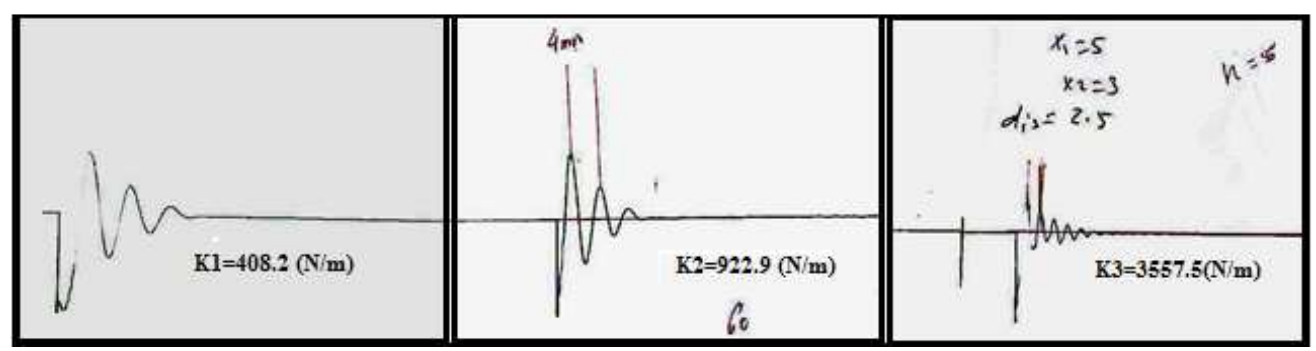

Figure 8: The Practical Test Results of the Response of Dash Pot Using the Plotter Device

The theoretical test results of the response of the dash pot according to use three types of spring coefficient can be displayed with using Matlab program as shown in Figures 9 a, b and c respectively.

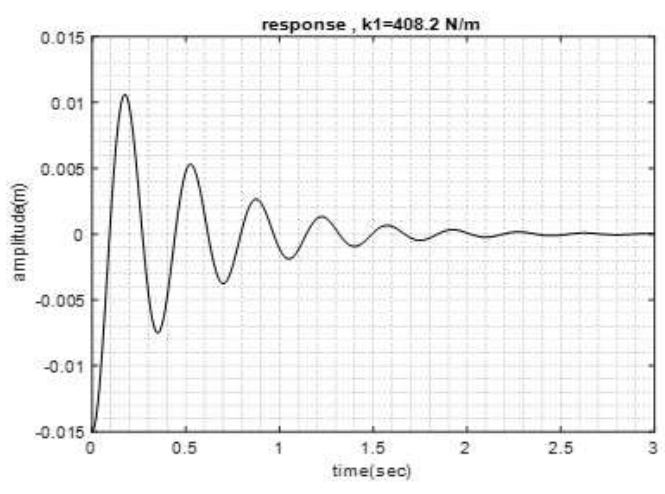

(a)

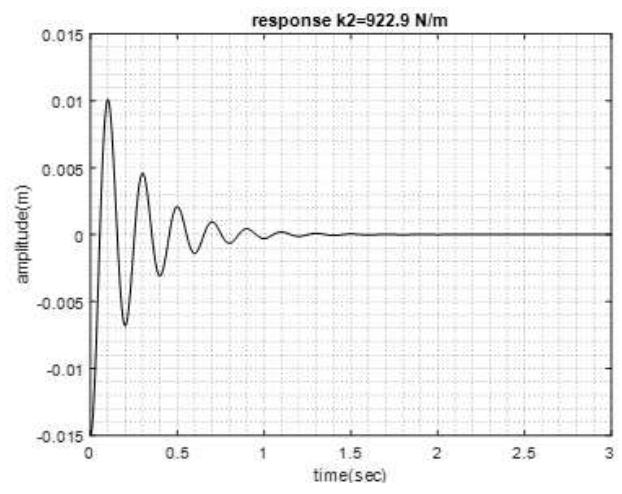

(b) 


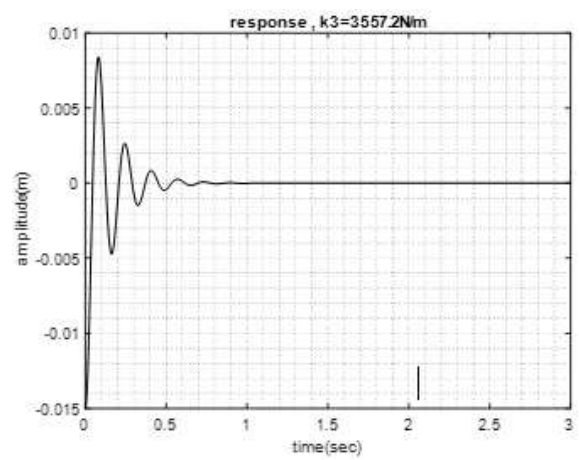

(c)

Figure 9: The Simulation Test Results of the Response of Dash -Pot Using Matlab

It can be listed the obtained results for the damping coefficient with using three different types of springs as shown in Table 5.

Table 5: Practical Results of Damping Coefficient of Dash-Pot

\begin{tabular}{|c|c|c|c|c|c|c|}
\hline Spring type & $\frac{\boldsymbol{x}_{\boldsymbol{o}}}{\boldsymbol{x}_{\mathbf{1}}}$ & $\boldsymbol{\delta}$ & $\begin{array}{c}\boldsymbol{\tau} \\
(\mathbf{s})\end{array}$ & $\boldsymbol{\zeta}$ & $\begin{array}{c}\boldsymbol{\omega}_{\boldsymbol{n}} \\
(\mathbf{r a d} / \mathbf{s})\end{array}$ & $\begin{array}{c}\mathbf{C} \\
(\boldsymbol{N s} / \mathbf{m})\end{array}$ \\
\hline 1 & $12 / 6$ & 0.693 & 0.35 & 0.1096 & 18.0680 & 17.889 \\
\hline 2 & $11 / 5$ & 0.788 & 0.2 & 0.12446 & 31.6748 & 26.898 \\
\hline 3 & $5.3 / 2.5$ & 0.751 & 0.105 & 0.11869 & 60.13944 & 52.800 \\
\hline
\end{tabular}

Based on steps 1 and 2 of the procedure of the experimental work in addition to calibration process the position sensor will detect the variable in displacement of the stroke of the equilibrium system and transferred it to different value of electrical resistance. The controller unit will convert these values of resistance to the corresponding electrical voltage signals and sent it to measurement device. This procedure represents the third step of experimental work and the obtained results for this step are listed as shown in Table 6.

Table 6: The Practical Results of Controlled Electromechanical System

\begin{tabular}{|c|c|c|c|}
\hline \multirow{6}{*}{$\begin{array}{c}\text { Spring (1) } \\
\text { with stiffness } \mathrm{K}_{1}=408.2 \mathrm{~N} / \mathrm{m}\end{array}$} & Load $(\mathrm{g})$ & Distance $(\mathrm{mm})$ & Voltage (V) \\
\hline & 400 & 5.5 & 0.47 \\
\hline & 800 & 6.3 & 0.6 \\
\hline & 1200 & 7.2 & 0.73 \\
\hline & 1600 & 8.1 & 0.87 \\
\hline & 2000 & 8.5 & 0.93 \\
\hline \multirow{6}{*}{$\begin{array}{c}\text { Spring (2) } \\
\text { with stiffness K2 }=922.9 \mathrm{~N} / \mathrm{m}\end{array}$} & Load $(\mathrm{g})$ & Distance $(\mathrm{mm})$ & Voltage (V) \\
\hline & 400 & 3.3 & 0.148 \\
\hline & 800 & 3.45 & 0.193 \\
\hline & 1200 & 4.0 & 0.268 \\
\hline & 1600 & 4.45 & 0.333 \\
\hline & 2000 & 4.9 & 0.406 \\
\hline \multirow{6}{*}{$\begin{array}{c}\text { Spring (3) } \\
\text { with stiffness K3=3557.5N/m }\end{array}$} & Load $(\mathrm{g})$ & Distance $(\mathrm{mm})$ & Voltage (V) \\
\hline & 400 & 5.1 & 0.420 \\
\hline & 800 & 5.1 & 0.422 \\
\hline & 1200 & 5.1 & 0.423 \\
\hline & 1600 & 5.2 & 0.444 \\
\hline & 2000 & 5.3 & 0.461 \\
\hline
\end{tabular}

It can be noted in Figures 8 and 9that the time elapsed to measure the theoretical and practical response for the three types of springs is done within $(3 \mathrm{~s})$. It is clearly founded from the plots in both figures that there is a quite matching 
between them. The percentage error for the obtained results was calculated as (11.66\%) for spring (1) and (8\%), (5.87\%) for springs (2), (3) respectively according to amplitude for the second cycle. To verify the step response of the controlled damper-mass spring system, it can be simulated using Matlab software package as shown in Figure 10 [17-20].

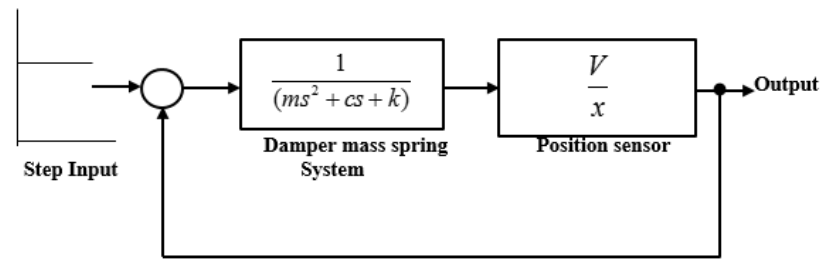

Figure 10: The Simulation Controlled Model of Damper Mass Spring System

As mentioned in Figure 10, the mathematical models of the open and closed loop controlled damper mass spring system can be estimated. The response of the system is depended on step input signal and the simulated closed loop model has been used unity feedback loop. If using two selected values of the applied mechanical load as a sample of calculation the first is equal to $400 \mathrm{~g}$ and the other is equal $2000 \mathrm{~g}$, then the obtained transfer function in equations (7) and (8) can be calculated as shown in Table 7.

Table 7: The Transfer Function of the Controlled Damper Mass Spring System $(\mathrm{K} 1=408.2 \mathrm{~N} / \mathrm{m}, \mathrm{C}=17.889 \mathrm{Ns} / \mathrm{m}),(\mathrm{K} 2=922.9 \mathrm{~N} / \mathrm{m}, \mathrm{C}=26.898 \mathrm{Ns} / \mathrm{m})$

$(\mathrm{K} 3=3557.5 \mathrm{~N} / \mathrm{m}, \mathrm{C}=\mathbf{5 2 . 8 0 0} \mathrm{Ns} / \mathrm{m})$

\begin{tabular}{|l|c|c|}
\hline Mass (g) & Open loop & \multicolumn{1}{c|}{ Closed loop } \\
\hline \multirow{3}{*}{400} & $T_{\text {open }}=\frac{85.45}{0.4 s^{2}+17.89 s+408.2}$ & $T_{\text {closed }}=\frac{85.45}{0.4 s^{2}+17.89 s+493.7}$ \\
\cline { 2 - 3 } & $T_{\text {open }}=\frac{44.85}{0.4 s^{2}+26.9 s+922.9}$ & $T_{\text {closed }}=\frac{44.85}{0.4 s^{2}+26.9 s+967.7}$ \\
\cline { 2 - 4 } & $T_{\text {open }}=\frac{82.35}{0.4 s^{2}+52.8 s+3558}$ & $T_{\text {closed }}=\frac{82.35}{0.4 s^{2}+52.8 s+3640}$ \\
\hline \multirow{3}{*}{2000} & $T_{\text {open }}=\frac{109.4}{2 s^{2}+17.89 s+408.2}$ & $T_{\text {closed }}=\frac{109.4}{2 s^{2}+17.89 s+517.6}$ \\
\cline { 2 - 3 } & $T_{\text {open }}=\frac{82.86}{2 s^{2}+26.9 s+922.9}$ & $T_{\text {closed }}=\frac{82.86}{2 s^{2}+26.9 s+1006}$ \\
\cline { 2 - 3 } & $T_{\text {open }}=\frac{86.98}{2 s^{2}+52.8 s+3558}$ & $T_{\text {closed }}=\frac{86.98}{2 s^{2}+52.8 s+3644}$ \\
\hline
\end{tabular}

According to the obtained results in Table7, the step response of the controlled electromechnical system with using different stiffness coefficients can be displayed in Figures. 11a, b and c respectively for value of load (400g) as well as Figures $12 \mathrm{a}, \mathrm{b}$ and $\mathrm{c}$ for $(2000 \mathrm{~g})$.

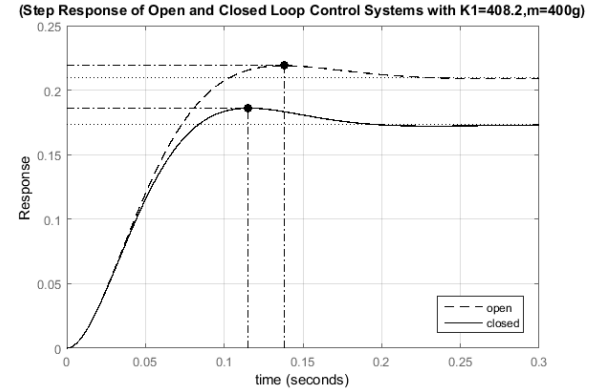

(a)

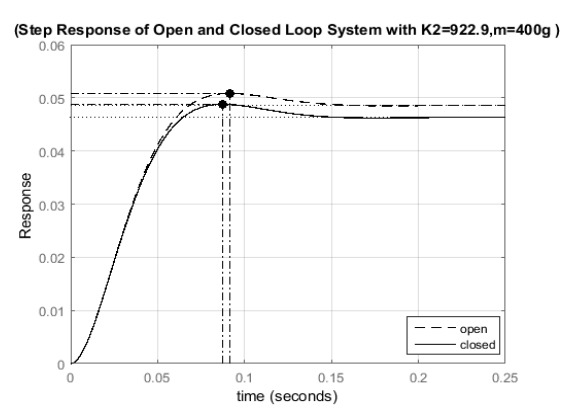

(b) 


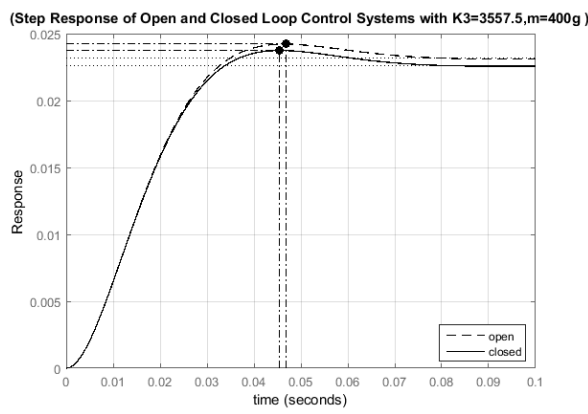

(c)

Figure 11: The Step Input Response of the Electromechanical System (400g)

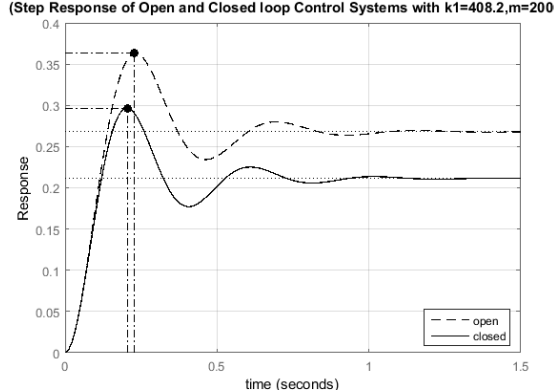

(a)

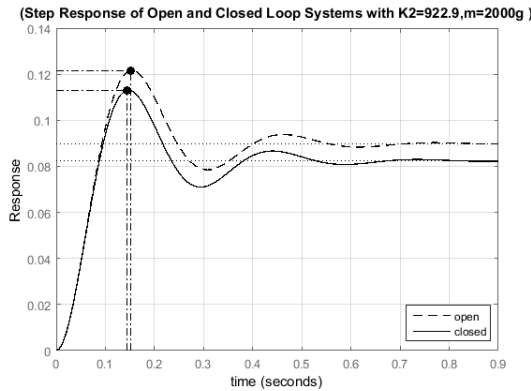

(b)

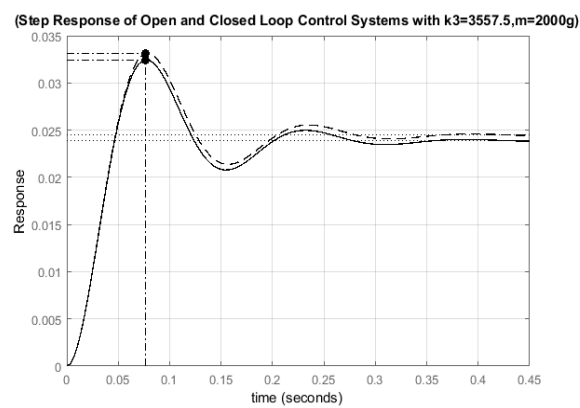

(c)

Figure 12: The Step Input Response of the Electromechanical System (2000g)

As mentioned in Figures 11 and 12, the peak amplitude of the step response for the simulation models of the controlled electromechanical damper mass spring system with using different stiffness coefficient can be listed as shown in Table8.

Table 8: The Results of the Step Response for the Controlled Electromechnical Damper Mass Spring System

\begin{tabular}{|c|c|c|c|c|c|c|c|}
\hline \multirow{3}{*}{$\begin{array}{l}\text { control } \\
\text { system }\end{array}$} & \multirow{3}{*}{$\begin{array}{c}\text { Force } \\
(\mathbf{N})\end{array}$} & \multicolumn{6}{|c|}{ Stiffness Coefficient (N/m) } \\
\hline & & \multicolumn{2}{|c|}{$K_{1}=408.2$} & \multicolumn{2}{|c|}{$K_{2}=922.9$} & \multicolumn{2}{|c|}{$K_{3}=3557.5$} \\
\hline & & $\begin{array}{c}\text { Peak } \\
\text { amplitude }\end{array}$ & $\begin{array}{l}\text { Time } \\
\text { (ms) }\end{array}$ & $\begin{array}{c}\text { Peak } \\
\text { amplitude }\end{array}$ & $\begin{array}{l}\text { Time } \\
\text { (ms) }\end{array}$ & $\begin{array}{c}\text { Peak } \\
\text { amplitude }\end{array}$ & $\begin{array}{l}\text { Time } \\
(\mathrm{ms})\end{array}$ \\
\hline \multirow{2}{*}{ Open loop } & 4 & 0.219 & 318 & 0.0508 & 91.8 & 0.0242 & 46.7 \\
\hline & 200 & 0.363 & 277 & 0.122 & 151 & 0.0331 & 76.8 \\
\hline \multirow{2}{*}{ Closed loop } & 4 & 0.186 & 115 & 0.0486 & 87.7 & 0.0237 & 45.4 \\
\hline & 200 & 0.296 & 206 & 0.113 & 144 & 0.0325 & 76.8 \\
\hline
\end{tabular}


The simulation process using Matlab software package also has been carried out to verify the effect of the stiffness coefficient of the spring element beside the all values of the applied load on the response of the electromechanical damper mass spring system. Based on the practical and theoretical results which has previously obtained in Tables4, 5,6and 7, the step response of the simulation results can be displayed as shown in Figures.13a, b and c respectively.

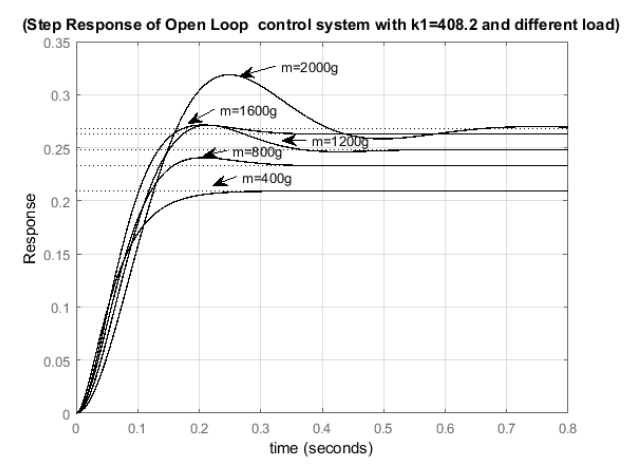

(a)

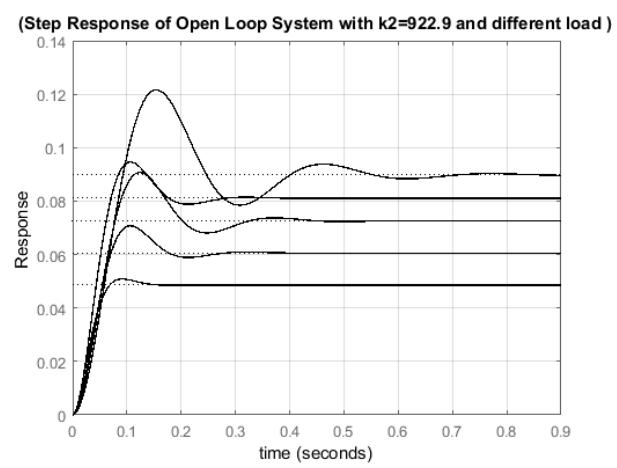

(b)

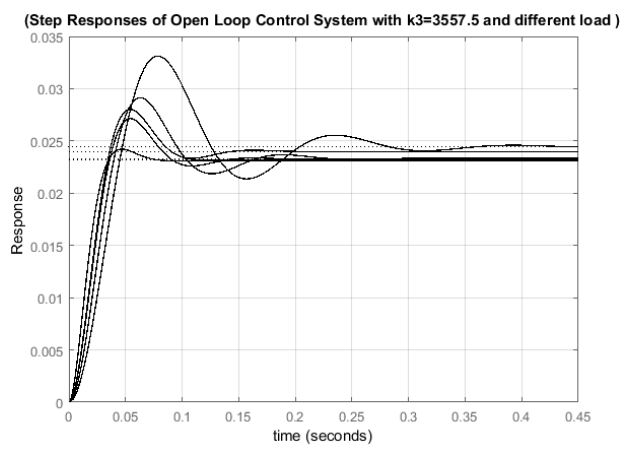

(c)

Figure 13: The Step Response of the Electromechanical System $(\mathrm{m}=400 \mathrm{~g}, 800 \mathrm{~g}, 1200 \mathrm{~g}, 1600 \mathrm{~g}$ and $2000 \mathrm{~g})$

\section{CONCLUSIONS}

The aim of this work is to observe the effect of using different types of spring coefficient on the response of the series combination damper mass spring system throughout using electromechanical position sensor. The application has been done with using adjustable value of mechanical load and electrical control unit. According to the obtained practical and simulation results, the following conclusions can be drawn from the present work:

- The applied configuration of the damper mass spring system has been vertically mounted and with increasing the stiffness coefficient of the selected spring causing decreasing in the rate of vibration on the system, in each value of applied force.

- Increasing the damping coefficient of the dash pot and increasing the value of stiffness coefficient of the spring causing an increasing in the calculated natural frequency of the system and reducing the tolerance in the stroke displacement of the system. It can be founded that the little bit difference between theoretical and practical results was appeared due to the accuracy of measurement devices which has been used to measure the tolerance of the displacement. 
- The simulation process showed that there is a quite a small difference in the step response results of the system between the open loop and closed loop control models.

- Although the employed control model is efficient and gave the required results but it can be modified and developed for better performance with using another types of controller model.

- The proposed controlled model of the electromechanical damper mass spring system can be considered as low applied cost model in relative to the applied mechanisms. It can be suitable implemented in many applications and laboratories.

\section{ACKNOWLEDGMENT}

The authors would like to thank and appreciate all valuable efforts of all colleagues in the Department of Mechanical Engineering, College of Engineering, Mustansiriyah University who have provided a benefit and helpful support which led to the achievement and improvement of this work.

\section{REFERENCES}

1. Razdan, S., Pathak, C. S., Bhave, S. Y. and Awasare, P. J., (2018). Mathematical modeling and simulation of quarter car model of an active air suspension. International Journal of Academic Research and Development, 3(1), pp.63-69.

2. Mirsanei, R., Hajikhani, A., Peykari, B. and Hamedi, J., (2012). Developing a new design for adaptive tuned dynamic vibration absorber (ATDVA) based on smart slider-crank mechanism to control of undesirable vibrations. International Journal of Mechanical Engineering and Mechatronics, 1(1), pp.80-87.

3. Aly, A. A. and Salem, F. A., (2013). Vehicle suspension systems control: a review. International journal of control, automation and systems, 2(2), pp.46-54.

4. Debbarma, R. and Hazari, S., (2013). Mass distribution of multiple tuned mass dampers for vibration control of structures under earthquake load. Int J EmergTechnolAdvEng, 3(8), pp.198-202.

5. Agharkakli, A., Sabet, G. S. and Barouz, A., (2012). Simulation and analysis of passive and active suspension system using quarter car model for different road profile. International Journal of Engineering Trends and Technology, 3(5), pp.636-644.

6. Bandivadekar, T. P. and Jangid, R. S., (2012). Mass distribution of multiple tuned mass dampers for vibration control of structures. International Journal of Civil and Structural Engineering, 3(1), pp.70-84.

7. Pawlus, W., Nielsen, J. E., Karimi, H. R. and Robbersmyr, K. G., (2010). Development of mathematical models for analysis of a vehicle crash. WSEAS Transactions on Applied and Theoretical Mechanics, 5(2), pp.156-165.

8. Julie, S. and Sajeeb, R., (2012). Performance of base isolators and tuned mass dampers in vibration control of a multistoried building. IOSR Journal of Mechanical and Civil Engineering, pp.2278-1684.

9. Kahyala, V. and Araz, O., (2017). Series tuned mass dampers in train-induced vibration control of railway bridges. Structural Engineering and Mechanics, 61(4), pp.453-461.

10. Singh, R. R., Gaikwad, Abhishek., Singh, S. S., \& Singh, V. P. (2015). Comparison of mechanical properties of medium carbon steel with dual phase steel. International Journal of Mechanical Engineering, 4(4), 1-8.

11. Chen, L., Sun, L. and Nagarajaiah, S., (2015). Cable with discrete negative stiffness device and viscous damper: Passive realization and general characteristics. Smart Structures and Systems, 15(3), pp.627-643. 
12. M. F. Badr, Yahya Abdullah, Ahmed KadhiamJaliel, (2017). Position control of the pneumatic actuator employing ON/OFF solenoids valve. International Journal of Mechanical Engineering and Mechatronics, Vol. 17, No. 2, pp. 29-37, IJENS publishing.

13. M. F. Badr, (2018). Modelling and Simulation of a Controlled Solenoid. In IOP Conference Series: Materials Science and Engineering, Vol. 433, No. 1, pp. 012082. IOP Publishing.

14. M. F. Badr,(2018). A Simplified Method for Energizing the Solenoid Coil Based on Electromagnetic Relays. ARPN Journal of Engineering and Applied Sciences, Vol. 13, No. 22, pp. 8750-8754, Asian Research Publishing Network (ARPN).

15. Thomson, W. T., (2012). Theory of vibration with application. PH Publishing, 5th edition, pp.27-30.

16. Raw, S. S., (1995). Mechanical vibration.3rd edition, Addision-Wiely Publishing Company, pp.298 -303.

17. Aguilar, J. F. G., García, J. R., Alvarado, J. B. and Guía, M., (2012). Mathematical modelling of the mass-spring-damper system-A fractional calculus approach. ActaUniversitaria, 22(5), pp.5-11.

18. Ogata, K., (2002). Modern control engineering”.4th edition, Pearson-Hall Publishing company, pp.128-138.

19. Raven, F. H., (1978). Automatic control engineering”.3rd edition, Mcgrew- hill Publishing company, pp.128 -138.

20. Yerrawar, R. N., Arakerimath, D. R., Rajendra, P. S. and Sambhaji, W. P., (2014). Performance Comparison of Semi-Active Suspension and Active Suspension System Using MATLAB/Simulink. International Journal of Innovative Research in Science, Engineering and Technology, Vol. 3, No.12, pp.18293-18299.

21. Davangeri, M. B., Vinay, B. U., \& Bhat, V. (2014). Development and Evaluation of Mechanical Properties of Asbestos Filled E-Glass/Epoxy Composites. Development, 4(1), 25-30.

22. M. F. Badr, (2014). Modelling and Simulation of Closed Loop Controlled DC-DC Converter Fed Solenoid Coil. Contemporary Engineering Sciences, Vol. 7, No.5, pp.207-217. 